\title{
Inflation Risk Hedging Strategy for Equities using Commodity Futures
}

\author{
Anurag Joshi
}

\begin{abstract}
The paper attempts to provide a possible hedging strategy against reduction in equity valuations due to inflation, using commodity futures. Commodity futures for four commodities namely pepper, steel, wheat and mustard seed are used along with sector equity indices of National Stock Exchange (NSE), India to determine plausible benefits of hedging equity risks with commodity futures. The effectiveness of the hedged portfolios is tested using standard statistical methods. The risk and return of a portfolio hedged with commodity future is compared with an equity only portfolio. The work thus provides an alternative hedging strategy against inflation for investors with primary investments in equities.
\end{abstract}

Index Terms - Commodity futures, hedging, inflation risk.

\section{INTRODUCTION}

Inflation has often been described as a necessary 'evil' counterpart of economic growth, as it helps in fuelling development in one hand, while eating into the profits and margins of companies on the other. The overall impact of inflation on a company's operations has been studied by academicians, stating how a positive impact on revenue is offset by increase in operating costs [1] - [5]. Moreover, a rise in inflation has been shown to adversely affect a company's equity valuation in the short term, thereby increasing the downside risk for investor [6].

Commodity prices have also been shown to be a leading indicator of inflation [7]. In recent times, due to complex inter-linkages, inflation may be affected by numerous factors. Spike in crude prices in oil markets translates into price rise across sectors in India, depending on government policies. Grain storage issues and rainfall also strongly affect the food inflation. But, the strong relation between commodity prices and inflation cannot be ignored. Moreover, the development of commodity derivatives market in India offers an important investment opportunity.

In an inflationary environment, the rise in price of commodities may be used to offset the fall in short-term equity valuations. Hence, commodities and its derivatives may provide a possible hedge against loss in value of assets due to inflation. Such a hedged portfolio would be useful for investors with high equity investments in an inflationary economy. Possibility and effectiveness of including commodities in a portfolio has been examined in this paper. The paper creates a portfolio of equities and commodity derivatives, and tests the efficacy of such a portfolio against loss in value using statistical analysis.

Manuscript received March 9, 2012; revised April 20, 2012.

A. Joshi is with Indian Institute of Management, Shillong (email: anurag.joshi2@gmail.com).
The remainder of the paper is organized as follows. section II provides a literature survey of the work done on effect of inflation on equity valuations and linkages between commodity prices and inflation. A description of research methodology is provided in section III followed by a section on data and analysis (section IV). The paper is finally concluded in section V.

\section{LITERATURE SURVEY}

Irving Fisher first stated that expected nominal rates of return on assets should move along with expected inflation [8]. Others studies also document the negative co-variation between actual equity returns and actual inflation [2], [9]. It has also been observed that both expected and unexpected inflation are negatively related to stock returns [5]. Hence, a predominant academic view, which continues to be reflected in the literature, is that high expected inflation predicts low stock returns, a perspective largely based upon the analysis of monthly and quarterly returns [10]. The negative relation between equity valuations and expected inflation is found to be the result of a rise in expected inflation coinciding with both lower expected real earnings growth and higher required real returns [10]. An increase in inflation firstly affects the cost base of companies (more for the ones with high operating leverage), and then also increases the rate of expected return. Brokers quickly adjust the estimates based on inflation levels thereby affecting a company's market valuation. Moreover, it has been found that the negative effect of both expected and unexpected inflation on stock returns tends to be largest for industries whose output is most cyclical and most negatively correlated with expected inflation [12].

Commodity prices are argued to be leading indicators of inflation as they respond more quickly to general economic shocks, such as an increase in demand [6]. Also, commodity prices are set in competitive auction markets and tend to be more flexible than prices overall. As a result, movements in commodity prices would be expected to lead and be positively related to changes in aggregate price inflation in response to aggregate demand shocks [13]. Furlong and Ingenito have also found that while inflation and commodity prices have a strong link, commodity prices cannot be used independently to forecast inflation [6].

Works regarding the identification of assets with negative correlation with equities have identified crude, gold and land assets as investment opportunities [14]. Most of the research is focused on the negative correlation between equities and the respective assets under inspection, however an inflationary impact on price movements has generally been ignored. 
The paper examines a possible advantage of using a commodity derivative in an equity portfolio in an inflationary environment where equity prices reduce while commodity prices tend to increase.

\section{DATA AND RESEARCH METHODOLOGY}

A methodology using standard valuation and statistical techniques is followed in arriving at evidence in support of using commodity derivatives as part of portfolio for hedging inflation risk. Previous works [2]- [6], have already confirmed the negative impact of inflation on equity valuations. Moreover, the strong link between commodity prices and inflation has already been established and need not be investigated further. Thus, building upon previous approaches, the paper tests the effect of commodity futures on portfolio returns. For simplicity, a portfolio comprising of a sector equity index and a commodity future is assumed. The returns on such a portfolio are compared against returns on an equity investment in the respective index only. The research methodology along with the data used is described in greater detail below.

\section{A. Selection of Sector Equity Indices And Commodity Futures}

Sector indices are chosen over specific company equities to nullify the effect of specific company based events on the share price of a company and provide a broad indicator for an industry/sector. The sectors chosen are FMCG, Energy and Auto while the commodities are pepper, wheat, steel long and mustard seed. Sector indices data is sourced from NSE while the commodity derivatives data is sourced from National Commodities and Derivatives Exchange (NCDEX), India.

In the data used for analysis, pepper and wheat futures contracts end on 11 Dec. 2011, steel long futures contract ends on 11 Nov. 2011 and mustard seed futures contract ends on 11 Oct. 2011. The analysis period is taken from 10 Jun 2011 to 20 Oct. 2011.

\section{B. Shortlisting Equity-Commodity Futures Combinations}

In order to select equity-commodity combination a correlation of equity index value with the commodity price is performed. The combinations with strong negative correlation are filtered out for the next stage of analysis, as only these would a proper hedge.

\section{Valuation of Portfolio and Calcuation of Portfolio Returns}

A portfolio of equity and commodity futures needs to be valued by finding the value of equity portion of the portfolio and then summing it with the value for the commodity futures part.

$$
V_{p_{(e, c)}}(t)=V_{e}(t)+V_{c}(t)
$$

where Vp represents the value of the portfolio at time $t$. $\mathrm{Ve}$ represents the value of the equity portion of the portfolio while $\mathrm{Vc}$ represents the value of the commodity futures included in the portfolio. The value of the equity portion of the portfolio can be calculated using the following formula

$$
V_{e}(t)=\sum_{i=1}^{m} n_{i}(t) \times p_{i}(t)
$$

where $\mathrm{m}$ is the total no. of equities in the portfolio, $\mathrm{p}$ represents the price of the equity $i$ with number of shares $n$ in the portfolio. Value Vc of q commodity futures, with the value $\mathrm{v}$ of $\mathrm{jth}$ commodity with $\mathrm{k}$ contracts can be given by

$$
V_{c}(t)=\sum_{j=1}^{q} k_{j}(t) \times v_{j}(t)
$$

where

$$
v_{j}(t)=f_{j}(t) \times e^{-\left(r_{f} \times(T-t)\right)}
$$

where $f$ is the futures price of the commodity expiring at time $T$, while $r_{f}$ is the risk free rate, interest rate on 91 days' T-bill issued by Reserve Bank of India (RBI) [15]. Return $r_{t}$ for a portfolio is given by

$$
r_{t}=\left(\frac{V_{p}(t)}{V_{p}(t-1)}-1\right) \times 100
$$

For simplicity $m=1$ and $q=1$.

\section{Testing the Efficacy of Portfolio Returns against Equity Returns}

After the calculation of portfolio returns, it needs to be confirmed whether a portfolio of equity and commodity future provided better returns than an equity alone portfolio. In order to prove that average returns for a portfolio of equity and commodity future is greater than returns on only equities portfolio, the following hypothesis needs to be accepted.

$$
H_{0}: \mu_{V_{p(e, c)}}>\mu_{V_{p(e)}}
$$

The hypothesis is tested using t-statistics for $95 \%$ confidence interval. A positive result would prove our assumption correct. Assuming an initial portfolio value of 100 , and varying the percentage of commodity futures in the initial investment, various cases are generated.

\section{E. Risk Return Profiling}

After the calculation of portfolio returns, it needs to be confirmed whether a portfolio of equity and commodity future provided better returns than an equity alone portfolio. In order to prove that average returns for a portfolio of equity and commodity future is greater than returns on only equities portfolio, the following hypothesis needs to be accepted.

$$
H_{0}: \mu_{V_{p(e, c)}}>\mu_{V_{p(e)}}
$$

The hypothesis is tested using t-statistics for $95 \%$ confidence interval. A positive result would prove our assumption correct. Assuming an initial portfolio value of 100 , and varying the percentage of commodity futures in the initial investment, various cases are generated. 


\section{RESULTS}

As preliminary analysis a correlation between the equity indices and commodity futures price is performed. The result is summarized in Table I. For the next stage of analysis, only combinations with negative correlation are used, since only these combinations may be useful in a hedging portfolio. Hence the following four portfolios are used.

\section{P1: FMCG and Pepper}

P2: Auto and Pepper

P3: Energy and Pepper

$P 4$ : Energy and Steel long

TABLE I: CORRELATION TABLE FOR EQUITY INDICES AND COMMODITY FUTURES

\begin{tabular}{lcccc}
\hline \hline & Pepper & Wheat & Steel long & Mustard seed \\
\hline FMCG & -0.32 & 0.32 & 0.13 & 0.42 \\
Auto & -0.19 & 0.22 & 0.06 & 0.09 \\
Energy & -0.75 & 0.77 & -0.38 & 0.28 \\
\hline \hline
\end{tabular}

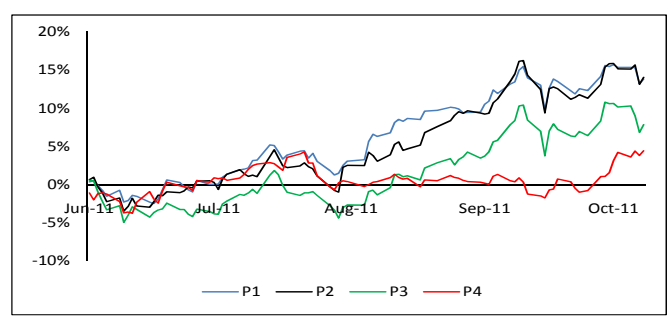

Fig. 1. (a) Daily returns for portfolios with $50 \%$ equity and $50 \%$ commodity futures.

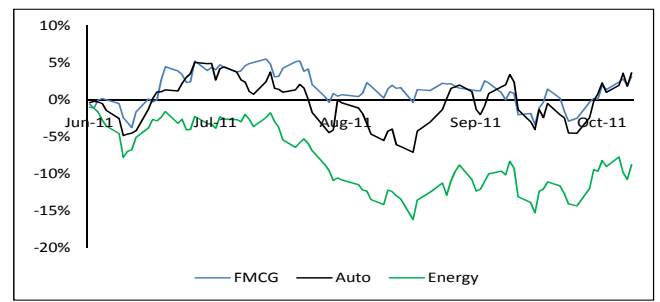

Fig. 1. (b) Daily returns for $100 \%$ equity.

TABLE II: RESULTS FOR 10\% EQUITY PORTFOLIO AND EQUITY INDEX

\begin{tabular}{lcccc}
\hline \hline & P1-FMCG & P2-Auto & P3-Energy & P4-Energy \\
\hline $\boldsymbol{\mu}_{\text {portfolio }}$ & $10.0 \%$ & $9.8 \%$ & $9.1 \%$ & $1.3 \%$ \\
$\boldsymbol{\mu}_{\text {equity }}$ & $1.5 \%$ & $-0.3 \%$ & $-7.9 \%$ & $-7.9 \%$ \\
$\boldsymbol{\sigma}_{\text {portfolio }}$ & $10.9 \%$ & $10.9 \%$ & $10.6 \%$ & $2.0 \%$ \\
$\boldsymbol{\sigma}_{\text {equity }}$ & $2.2 \%$ & $3.0 \%$ & $4.3 \%$ & $4.3 \%$ \\
$\boldsymbol{\mu}_{\text {portfolio/ }} \boldsymbol{\sigma}_{\text {portfolio }}$ & 0.92 & 0.90 & 0.85 & 0.63 \\
$\boldsymbol{\mu}_{\text {equity }} \boldsymbol{\sigma}_{\text {equity }}$ & 0.67 & -0.10 & -1.85 & -1.85 \\
Sharpe ratio & & & & \\
t statistic & 7.3 & 8.5 & 14.1 & 18.4 \\
p-value & 1.0000 & 1.0000 & 1.0000 & 1.0000 \\
\hline \hline
\end{tabular}

The daily returns for each of these four portfolios are calculated and compared with daily returns for individual equity indices. Figure 1(a) and 1(b) show the variation of returns for the portfolios $(P 1, P 2, P 3$ and $P 4)$ assigning equal weights to equity and commodity futures and daily returns for equity indices only.
The difference in returns is visible from the figures above, however the sample needs to be statistically tested. To confirm the hypothesis $H_{0}$ (equation 5) standard t-statistic is used. It is assumed that the variance of the portfolio returns $(P 1, P 2, P 3$ and $P 4)$ is not equal to the variance in returns for the respective equity index. The results of the statistical tests under various equity-commodity combinations are presented in a tabular format (Table II - Table VI). The sample size for all cases is 90 .

The statistical analysis proves that inclusion of commodity futures provided higher returns than an equity alone portfolio. The commodity included portfolios tend to have larger risk (standard deviation) than equity only portfolios, however the increase in risk is compensated by the simultaneous increase in returns. The average return per unit risk (standard deviation) tends to be higher for a commodity included portfolio. The tests were accepted with $95 \%$ confidence, implying that overall, an inclusion of commodity futures in an equity portfolio, provides a better hedge in an inflationary environment.

TABLE III: RESULTS FOR 30\% EQUITY PORTFOLIO AND EQUITY INDEX

\begin{tabular}{ccccc}
\hline \hline & P1-FMCG & P2-Auto & P3-Energy & P4-Energy \\
\hline $\boldsymbol{\mu}_{\text {portfolio }}$ & $8.1 \%$ & $7.6 \%$ & $5.3 \%$ & $0.2 \%$ \\
$\boldsymbol{\mu}_{\text {equity }}$ & $1.5 \%$ & $-0.3 \%$ & $-7.9 \%$ & $-7.9 \%$ \\
$\boldsymbol{\sigma}_{\text {portfolio }}$ & $8.3 \%$ & $8.4 \%$ & $7.6 \%$ & $2.0 \%$ \\
$\boldsymbol{\sigma}_{\text {equity }}$ & $2.2 \%$ & $3.0 \%$ & $4.3 \%$ & $4.3 \%$ \\
$\boldsymbol{\mu}_{\text {portfolio/ }} \boldsymbol{\sigma}_{\text {portfolio }}$ & 0.98 & 0.90 & 0.70 & 0.09 \\
$\boldsymbol{\mu}_{\text {equity/ }} \boldsymbol{\sigma}_{\text {equity }}$ & 0.67 & -0.10 & -1.85 & -1.85 \\
$\mathbf{t}$ statistic & 7.3 & 8.4 & 14.4 & 16.3 \\
p-value & 1.0000 & 1.0000 & 1.0000 & 1.0000 \\
\hline \hline
\end{tabular}

TABLE IV: RESULTS FOR 50\% EQUITY PORTFOLIO AND EQUITY INDEX

\begin{tabular}{lcccc}
\hline \hline & P1-FMCG & P2-Auto & P3-Energy & P4-Energy \\
\hline $\boldsymbol{\mu}_{\text {portfolio }}$ & $6.2 \%$ & $1.5 \%$ & $0.5 \%$ & $6.2 \%$ \\
$\boldsymbol{\mu}_{\text {equity }}$ & $1.5 \%$ & $-7.9 \%$ & $-0.4 \%$ & $1.5 \%$ \\
$\boldsymbol{\sigma}_{\text {portfolio }}$ & $5.8 \%$ & $4.7 \%$ & $1.8 \%$ & $5.8 \%$ \\
$\boldsymbol{\sigma}_{\text {equity }}$ & $2.2 \%$ & $4.3 \%$ & $2.5 \%$ & $2.2 \%$ \\
$\boldsymbol{\mu}_{\text {portfolio }} \boldsymbol{\sigma}_{\text {portfolio }}$ & 1.07 & 0.32 & 0.31 & 1.07 \\
$\boldsymbol{\mu}_{\text {equity }} \boldsymbol{\sigma}_{\text {equity }}$ & 0.67 & -1.85 & -0.16 & 0.67 \\
$\mathbf{t}$ statistic & 7.2 & 14.1 & 2.9 & 7.2 \\
$\mathbf{p}$-value & 1.0000 & 0.9980 & 1.0000 & 1.0000 \\
\hline \hline
\end{tabular}

TABLE V: RESULTS FOR 70\% EQUITY PORTFOLIO AND EQUITY INDEX

\begin{tabular}{lcccc}
\hline \hline & P1-FMCG & P2-Auto & P3-Energy & P4-Energy \\
\hline $\boldsymbol{\mu}_{\text {portfolio }}$ & $4.3 \%$ & $3.1 \%$ & $-2.3 \%$ & $0.9 \%$ \\
$\boldsymbol{\mu}_{\text {equity }}$ & $1.5 \%$ & $-0.3 \%$ & $-7.9 \%$ & $-7.9 \%$ \\
$\boldsymbol{\sigma}_{\text {portfolio }}$ & $3.5 \%$ & $3.8 \%$ & $2.4 \%$ & $1.8 \%$ \\
$\boldsymbol{\sigma}_{\text {equity }}$ & $2.2 \%$ & $3.0 \%$ & $4.3 \%$ & $4.3 \%$ \\
$\boldsymbol{\mu}_{\text {portfolio }} \boldsymbol{\sigma}_{\text {portfolio }}$ & 1.25 & 0.80 & -0.94 & 0.51 \\
$\boldsymbol{\mu}_{\text {equity }} \boldsymbol{\sigma}_{\text {equity }}$ & 0.67 & -0.10 & -1.85 & -1.85 \\
$\mathbf{t}$ statistic & 6.6 & 6.6 & 10.9 & 18.0 \\
p-value & 1.0000 & 0.9980 & 1.0000 & 1.0000 \\
\hline \hline
\end{tabular}

TABLE VI: RESULTS FOR 90\% EQUITY PORTFOLIO AND EQUITY INDEX

\begin{tabular}{lcccc}
\hline \hline & P1-FMCG & P2-Auto & P3-Energy & P4-Energy \\
\hline $\boldsymbol{\mu}_{\text {portfolio }}$ & $2.4 \%$ & $0.8 \%$ & $-6.1 \%$ & $1.3 \%$ \\
$\boldsymbol{\mu}_{\text {equity }}$ & $1.5 \%$ & $-0.3 \%$ & $-7.9 \%$ & $-7.9 \%$ \\
$\boldsymbol{\sigma}_{\text {portfolio }}$ & $2.0 \%$ & $2.7 \%$ & $3.1 \%$ & $2.0 \%$ \\
$\boldsymbol{\sigma}_{\text {equity }}$ & $2.2 \%$ & $3.0 \%$ & $4.3 \%$ & $4.3 \%$ \\
$\boldsymbol{\mu}_{\text {portfolio/ }} \boldsymbol{\sigma}_{\text {portfolio }}$ & 1.24 & 0.31 & -1.98 & 0.63 \\
$\boldsymbol{\mu}_{\text {equity }} \boldsymbol{\sigma}_{\text {equity }}$ & 0.67 & -0.10 & -1.85 & -1.85 \\
t statistic & 3.0 & 2.7 & 3.4 & 18.4 \\
p-value & 0.9986 & 0.9958 & 0.9996 & 1.0000 \\
\hline \hline
\end{tabular}




\section{CONCLUSION AND SugGestions}

It can be concluded that addition of commodity futures to and equity portfolio can provide better returns than an equity only portfolio. Moreover, in an inflationary environment these commodity derivatives can provide a hedge against a probable short-term fall in equity prices. However, the commodity derivative should be selected carefully, keeping in mind the assets already included in the portfolio. Also, inflation tends to be accompanied by rise in policy rates, leading to a rise in government bond yields, which thereafter negatively affects the risk premium any portfolio can offer, as seen from the Sharpe ratios for the various portfolios studied. In such situations, it may be prudent to avoid risky investments altogether.

However, the work done provides a framework for detail analysis for individual investors working with defined equity portfolios. Fund management firms always seek new investment strategies maintaining a defined risk-return profile. The above work would be useful for such firms engaged in quantitative analysis of portfolios and interested in commodities market.

The analysis does leave scope for further work which can be made more elaborate including a larger time frame or a wider spectrum of commodity derivatives. The analysis can be extended to developed commodity markets globally to have better benchmarks for comparison.

In conclusion, the research serves as a useful tool for equity investors suggesting commodity derivatives as an interesting investment alternative.

\section{REFERENCES}

[1] F. Diebold and K. Yilmaz, "Measuring financial asset return and volatility spillovers, with application to global equity markets," The Economic Journal, vol. 119, pp 158-171, 2009.

[2] J. Lintner, "Inflation and security return," Journal of Finance, vol. 30, pp. 259-80, 1975.
[3] K. French, R. Ruback, and G.W. Schwert, "Effects of nominal contracting on stock returns," Journal of Political Economy, vol. 91, pp. 70-96, 1983.

[4] E. Fama and K. French, "Business conditions and expected returns on stocks and bonds," Journal of Financial Economics, vol. 25, pp. 2349, 1989.

[5] E. Fama and G. W. Schwert, "Asset returns and inflation," Journal of Financial Economics, vol. 5, pp. 115-146, 1977.

[6] S. A. Sharpe, "Reexamining stock valuation and inflation: the implications of analysts' earnings forecasts," Division of Research and Statistics, Federal Reserve Board, Working Paper, July 2000.

[7] F. Furlong and R. Ingenito, "Commodity prices and inflation," FRBSF Economic Review, no. 2, 1996.

[8] I. Fisher, "The theory of interest," New York, McMillan, 1930.

[9] Z. Bodie, "Common stocks as a hedge against inflation," Journal of Finance, vol. 31, pp. 459-470, 1976.

[10] M. Barnes, J. H. Boyd, and B. D. Smith, "Inflation and Asset Returns," European Economic Review, no. 43, pp. 737-754, 1999.

[11] R. Pindyck, "Risk, inflation, and the stock market," Massachusetts Institute of Technology, wp. 1482-83,1983.

[12] J. Boudoukh and M. Richardson, "Stock returns and inflation: A long horizon perspective," American Economic Review, vol. 83, pp. 1346$1355,1993$.

[13] J. Boughton, and W. Branson, "Commodity Prices as a Leading Indicator of Inflation,” NBER, working paper no. 2750, 1988.

[14] F. Kenneth, "Hedging portfolios with real assets," A Journal of Portfolio Management, vol. 21, no. 4, pp. 60-77, 1995.

[15] J. Hull and S. Basu, "Options, futures and other derivatives" $7^{\text {th }}$ edition, Pearson, ISBN 978-81-317-2358-6, pp. 55-140, 2010.

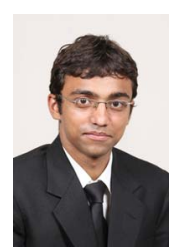

Anurag Joshi, Dehradun (India), 1987. Anutag has done his PGDM from the Indian Institute of Management, Shillong. Anurag also holds a dagree in Bachelors of Technology in Electronics and Communication from Motilal Nehru National Institute of Technology, Allahabad (India). Anurag is currently working in the Investment Banking division of a leading global bank and his interests include commodity derivatives and financial strategy. 